\title{
Исследование пространственного распределения люминесценции в диапазоне 0.44-0.75 мкм CVD-ZnSe, легированного алюминием и железом
}

\author{
(C) В.П. Калинушкин ${ }^{1}$, А.А. Гладилин ${ }^{1}$, О.В. Уваров ${ }^{1}$, С.А. Миронов ${ }^{1,{ }^{\top}}$, Н.Н. Ильичев ${ }^{1}$, \\ М.И. Студеникин ${ }^{1}$, В.А. Чапнин ${ }^{1}$, Н.A. Тимофеева ${ }^{2}$, Е.М. Гаврищук ${ }^{2}$, \\ C.А. Родин ${ }^{2}$, В.Б. Иконников ${ }^{2}$, Г.Г. Новиков ${ }^{3}$ \\ ${ }^{1}$ Институт общей фризики им. А.М. Прохорова Российской академии наук, \\ 119991 Москва, Россия \\ ${ }^{2}$ Институт химии высокочистых веществ им. Г.Г. Девятых Российской академии наук, \\ 603951 Нижний Новгород, Россия \\ ${ }^{3}$ Национальный исследовательский ядерный университет „МИФИ“, \\ 115409 Москва, Россия \\ IE-mail: sa.mironov@kapella.gpi.ru
}

Поступила в Редакцию 12 января 2021 г.

В окончательной редакции 25 января 2021 r.

Принята к публикации 25 января 2021 г.

Детально исследовано пространственное распределение люминесцентных характеристик CVD-ZnSe, легированного алюминием и алюминием и железом методом термодиффузии. Обнаружено, что методика легирования алюминием, используемая в данной работе, приводит к образованию в кристаллах двух областей: области с большей концентрацией алюминия, в которой доминирует люминесценция примесно-дефектных центров и отсутствует экситонная люминесценция и области с меньшей концентрацией алюминия, в которой доминирует экситонная люминесценция. Установлено, что границы этих областей, регистрируемые с помощью люминесценции, несут резкий, нехарактерный для диффузионных процессов характер. Этот результат объясняется в предположении аномального характера диффузии алюминия, приводящего к резкому изменению концентрации алюминия на некотором расстоянии от поверхности, с которой проводилось легирование. Показано, что применяемая в данной работе методика легирования алюминием кристаллов $\mathrm{ZnSe}$ ослабляет известный эффект подавления железом люминесценции $\mathrm{ZnSe}$ в видимом диапазоне.

Ключевые слова: CVD-ZnSe, двухфотонное поглощение, термодиффузия, железо, алюминий.

DOI: 10.21883/FTP.2021.05.50829.9614

\section{1. Введение}

ИК-лазеры, генерирующие в диапазоне 4-5 мкм, на легированных ионами $\mathrm{Fe}^{2+}$ кристаллах $\mathrm{ZnSe}$ перспективны для широкого спектра применений в различных областях науки и техники. Создание эффективных источников на активных средах $\mathrm{ZnSe}: \mathrm{Fe}^{2+}$ связано как с развитием технологий выращивания легированных кристаллов, так и с вариацией источников возбуждения лазерной генерации. В настоящее время высокие лазерные характеристики (1.4 Дж при $\eta_{\text {slope }}=52 \%$ и $\eta_{\text {abs }} \approx 48 \%$ ) достигнуты, например, на поликристаллических образцах $\mathrm{ZnSe}$, легированных ионами железа методом диффузии [1-3]. В качестве источника возбуждения при этом использовался электроразрядный НF-лазер. Однако в связи со сложностью конструкции и значительными габаритами использование таких систем накачки практически невозможно для создания компактных мобильных источников ИК-излучения. Альтернативным способом накачки активных сред на ионах переходных металлов может быть создание инверсной населенности с помощью ударной ионизации ионов активатора „горячими“ (с энергией несколько эВ) электронами. Одним из способов увеличения концентрации электронов в кристаллах
$\mathrm{ZnSe}$ является введение дополнительной трехвалентной примеси, например, Al [4-6]. В работах [7,8] были рассмотрены механизмы переходов $\mathrm{Cr}^{2+}$ при совместном легировании кристаллов $\mathrm{ZnSe}: \mathrm{Al}: \mathrm{Cr}$ и получена электролюминесценция на этих материалах.

Однако информация о систематических исследованиях примесно-дефектного состава и его пространственного распределения в кристаллах $\mathrm{ZnSe}: \mathrm{Al}: \mathrm{Fe}$ и $\mathrm{ZnSe}: \mathrm{Al}: \mathrm{Cr}$ в доступной литературе отсутствует. Для изучения влияния накачки ионов активатора горячими носителями тока необходима детальная информация об этих характеристиках. Данная работа посвящена исследованию примесно-дефектного состава CVD-ZnSe сильно легированного алюминием и солегированного алюминием и железом.

\section{2. Описание эксперимента}

В работе были исследованы поликристаллические образцы.

- Образец 1 был легирован по следующей методике: заготовку CVD-ZnSe помещали в кварцевую ампулу с источником алюминия, размешенным в графитовом 
тигле, и проводили диффузионный отжиг в атмосфере $\mathrm{Zn}$ в течение 20 ч при $T=1050^{\circ} \mathrm{C}$. В результате образец легировался алюминием со всех сторон. Далее полученный образец $\mathrm{ZnSe}: \mathrm{Al}$ подвергался высококачественному химико-механическому полированию. Согласно измерениям эффекта Холла было определено, что концентрация свободных носителей равна $1.4 \cdot 10^{16} \mathrm{~cm}^{-2}$ ( $n$-тип).

- Образец 2 был изготовлен по следующей методике: первоначально выполнялось легирование образцов CVD-ZnSe ионами железа. На противоположные полированные поверхности заготовки методом электронно-лучевого испарения наносилась пленка железа ( 1 мкм), затем образец помещался в камеру, в которой отжигался при температуре $T=1250^{\circ} \mathrm{C}$ и давлении аргона в камере $P=950$ МПа. Время обработки составляло 22 ч. Введение примеси $\mathrm{Al}$ в полученный образец $\mathrm{ZnSe}: \mathrm{Fe}$ осуществлялось при тех же параметрах диффузионного отжига, что и для образца 1. Таким образом, легирование алюминием проходило со всех сторон, а железом - с двух противоположных. Для проведения оптических измерений образец $\mathrm{ZnSe}: \mathrm{Al}$ : $\mathrm{Fe}$ подвергался высококачественному химико-механическому полированию. Согласно измерениям эффекта Холла было определено, что концентрация свободных носителей равна $7.1 \cdot 10^{15} \mathrm{~cm}^{-2}$ (n-тип).

При используемых методах легирования образцы имеют неоднородное по объему распределение характеристик. В связи с этим для исследования люминесценции использовалась двухфотонная конфокальная люминесцентная микроскопия (ДФКЛМ), которая позволяет исследовать люминесцентные характеристики с пространственным разрешением в несколько мкм. В данной работе использовался конфокальный микроскоп фирмы CarlZeiss LSM 710 NLO. Двухфотонное возбуждение осуществлялось лазером с перестраиваемой длиной волны в диапазоне 0.71-1.05 мкм (в данной работе использовалось излучение с длиной волны 0.8 мкм). Длительность импульса составляла 150 фс, частота 80 МГц, максимальная средняя мощность 0.1-1 Вт варьировалась в зависимости от условий детектирования и оптимизировалась для получения контрастного изображения люминесценции образца. Спектры люминесценции регистрировались в диапазоне 440-725 нм со спектральным разрешением 10 нм. Эти параметры эффективны для исследования кристаллического $\mathrm{ZnSe}$, ширина запрешенной зоны которого составляет при $300 \mathrm{~K} \approx 2.7$ э. Таким образом, на этом приборе реализуется двухфотонное возбуждение неравновесных носителей и регистрация краевой и части дефектнопримесной люминесценции (в диапазоне 460-715 нм). Экспериментальное оборудование позволяло регистрировать и обрабатывать трехмерные картины распределения краевой и дефектно-примесной люминесценции исходных и легированных алюминием и железом кристаллов $\mathrm{ZnSe}$ на глубину до 3 мм с пространственным разрешением порядка нескольких микрометров. Время снятия одной объемной „карты“ на глубину 1 мм с
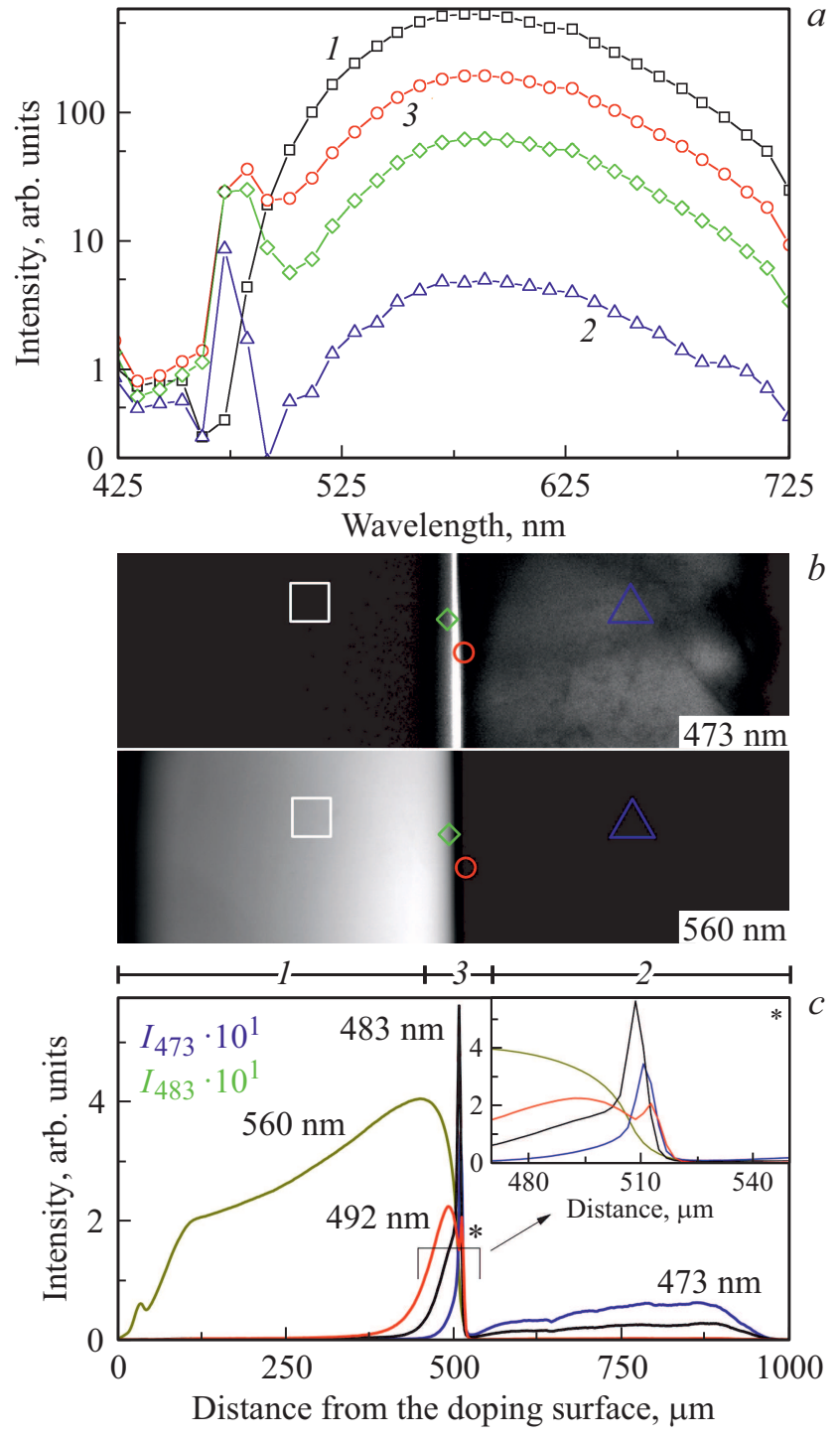

Рис. 1. Спектры люминесценции в логарифмическом масштабе $(a)$ из областей кристалла $\mathrm{ZnSe}: \mathrm{Al}$, обозначенных на картах люминесценции $(b)$, полученных на длинах волн 473 и 560 нм на глубине 100 мкм, а также распределение интенсивности люминесценции $(c)$ на длинах волн 473, 483, 492 и 560 нм из области записи карты. На вставке рис. 1, $c$ показана переходная область в увеличенном масштабе.

шагом 25 мкм и размером „плоской“ карты $1 \times 1$ мм составляло $\sim 5$ мин. Все эксперименты проводились при комнатной температуре. В данной работе в качестве основной методики используется техника исследования ДФКЛМ „с торца“, т. е. со скола, перпендикулярного поверхности, с которой проводилось легирование. Подробно эта методика описана в работах $[9,10]$. Распределение концентрации активных ионов $\mathrm{Fe}^{2+}$ вдоль направления диффузионного потока рассчитывали на основе данных о поглощении излучения на длине волны 2.8 мкм. Для этого использовался ИК-микроскоп HYPERION 2000 в комбинации с ИК фурье-спектрометром Tenzor-27 
(Bruker). Подробное описание методики сканирования представлено в работе [11].

\section{3. Результаты экспериментов}

Вначале рассмотрим результаты исследования образца $1 \mathrm{ZnSe}: \mathrm{Al}$. На рис. $1, b$ приведены плоские карты люминесценции на длинах волн 473 и 540 нм одной области образца и спектры люминесценции (рис. $1, a$ ) разных областей, отмеченных на карте. Эти карты были сняты по методике „с торца“. Расстояние от поверхности сколов составляло $\sim 100$ мкм. На рис. $1, c$ приведены зависимости интенсивности люминесценции от расстояния от поверхности, с которой проводилось легирование, из областей, показанных на карте рис. $1, b$ для длин волн 473, 483, 492 и 560 нм. Эти данные характеризуют образец 1 в целом. Они показывают, что этот кристалл можно разделить на три области, имеющие вид полос, параллельных плоскости, с которой осуществлялась диффузия примеси:

- область, примыкающая к этой поверхности (шириной $\sim 500$ мкм), - в этой области концентрация алюминия достаточно большая - в дальнейшем легированная область;

- область с более низкой концентрацией алюминия, занимающая часть кристалла за легированной областью, - в дальнейшем нелегированная область;

- узкая область между нелегированной и легированной областями - переходной слой.

На вставке рис. 1, $c$ показаны зависимости от расстояния от поверхности, с которой проводилось легирование, интенсивности люминесценции на длинах волн 473 , 483,492 и 560 нм. Эти рисунки более детально характеризуют переходную область поликристалла $\mathrm{ZnSe}: \mathrm{Al}$ в области 470-550 мкм от поверхности легирования. На рис. 2 приведены карты участка образца 1 размером $134 \times 134$ мкм, полученные со скола на расстоянии от поверхности скола $\sim 30$ мкм на длинах волн 473 и 560 нм. Спектры на рис. 2, $a, b$ были зарегистрированы в разных областях кристалла. Спектр на рис. 2, $a$ был получен при мощности накачки, в 4 раза меньшей, чем спектр, представленный на рис. $2, b$. Полученные данные показывают, что в легированной области доминирует люминесценция ПДЦ с широким спектром (от 500 до 725 нм), максимумом интенсивности люминесценции в районе 580 нм и особенностью в районе 630 нм (линия 580-630). Также был зарегистрирован спектр люминесценции в области 470-500 нм (линия 480) (рис. 1, $a$ ). Эта область образца 1 выглядит как полоса шириной $\sim 450$ мкм, с высокой интенсивностью люминесценции линии 540-630, параллельная поверхности, с которой проводилось легирование. Люминесцентные характеристики в ней практически не зависели от расстояния от поверхности скола.

Нелегированная область в этом образце характеризуется невысокой интенсивностью люминесценции линии с максимумом в области 473 нм и слабой по интенсивности широкой полосой $(500-700$ нм $)$ с максимумом интенсивности люминесценции в области 560 нм (рис. 1,a).

В переходной области наблюдается интенсивная узкая линия в диапазоне 473-483 нм, строго параллельная поверхности, с которой проводилось легирование (рис. $1, a)$. Небольшие искажения связаны с искривлением переходного слоя в районе границ зерен, пересекающих переходный слой (рис. 2). В спектре люминесценции этой области доминирует излучение с максимумом $\sim 475$ нм и регистрируется слабая люминесценция в области 580-630 нм.

Рассмотрим более подробно линии в районе $470-500$ нм. Как видно из рис. $1, a$, спектр люминесценции в переходной области и прилегающих к ней легированной и нелегированной областях в диапазоне $470-500$ нм существенно изменяется. В легированной области кристалла на расстоянии от поверхности, с которой шло легирование, $\sim 350$ мкм на полосе $580-630$ нм появляется особенность при $470-500$ нм. В переходной области образца эта особенность переходит в линию с максимумом интенсивности в районе 480 нм. При дальнейшем удалении от поверхности, с которой проводилось легирование, этот максимум сдвигается к 475 нм. Как отмечалось выше, в переходной области регистрируется линия с максимумом интенсивности 475 нм, а в нелегированной области - линия с максимумом 473 нм. При этом достаточно широкая линия 480 нм перекрывается и с линиями 473 и 475 нм. Еще более сильно перекрываются линии 475 и 473 нм. На рис. 2 приведены спектры люминесценции разных зон кристалла при разных уровнях накачки. На вставке рис. 1, с видно, что интенсивность линии $473 \mathrm{Hм} \mathrm{в}$ нелегированной области нарастает быстрее, чем интенсивность люминесценции линий 560, 580-630 и 480 нм. Сложнее поведение линии 475 нм. Интенсивность линии 473 нм растет быстрее, чем интенсивность линии 475 нм. Однако эта разница не столь очевидна, как в случае указанных выше линий.

Интенсивность люминесценции линии 580-630 нм в легированной области растет при увеличении расстояния от плоскости образца, с которой шло легирование. Увеличение интенсивности небольшое - в $\sim 2$ раза. Интенсивность достигает максимума на расстоянии $\sim 420$ мкм от поверхности и затем начинается резкий спад (рис. 1,c). Уменьшение интенсивности люминесценции линии $580-630$ нм в $\sim 40$ раз происходит на расстоянии $\sim 80$ мкм. Отметим, что такое пространственное распределение интенсивности характерно для всей люминесценции с длиной волны более 510 нм.

От поверхности легирования до 400 мкм линии 473 нм в спектре люминесценции не регистрируется. Интенсивность люминесценции этой линии растет примерно на 2 порядка при увеличении расстояния от поверхности, с которой проводилось легирование, от 450 до 510 мкм. Затем на расстоянии до 520 мкм происходит 

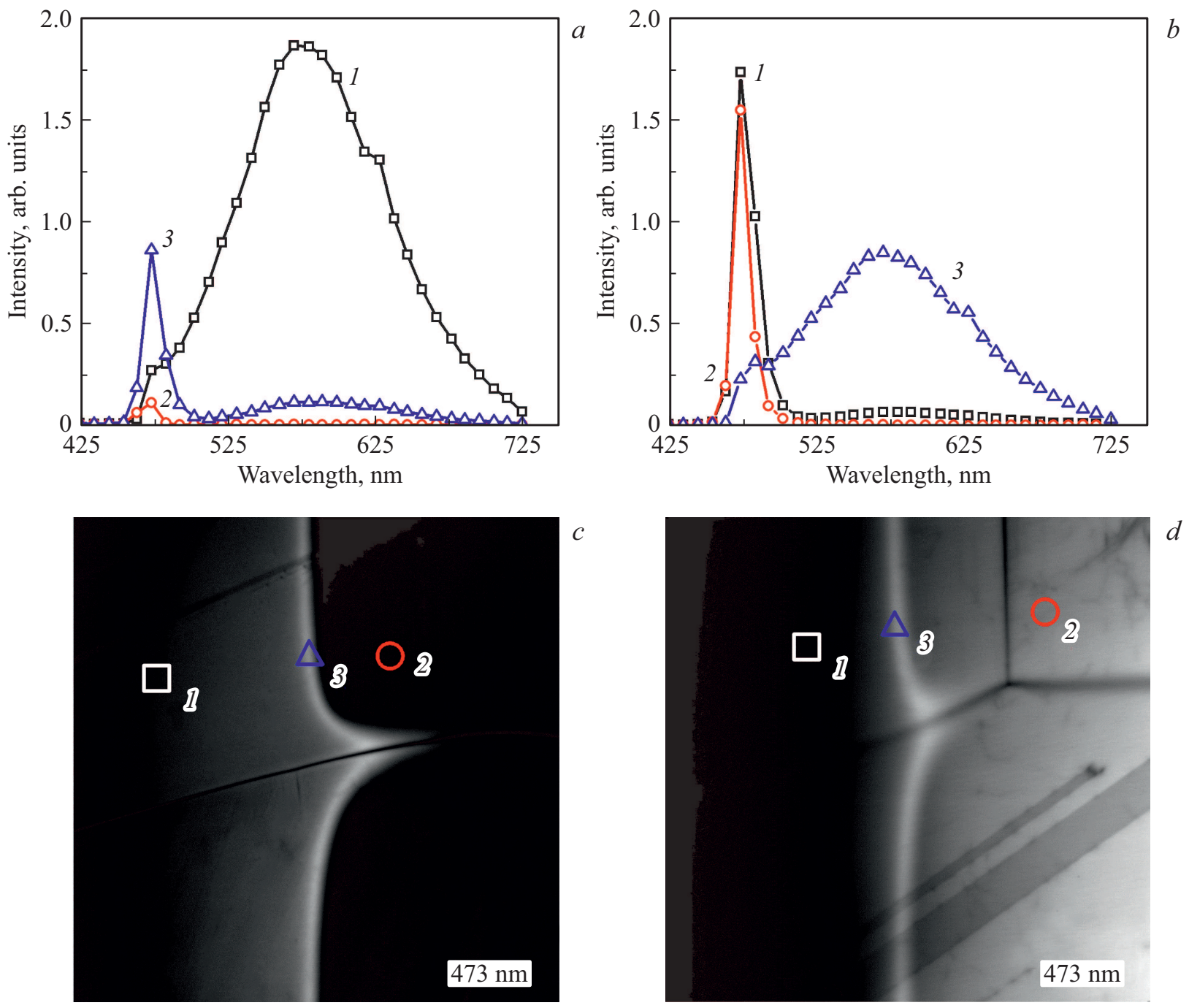

Рис. 2. Спектры люминесценции в области 425-725 нм, полученные при малой $(a)$ и большой $(b)$ мощности накачки, записанные в областях, обозначенных на картах $(c, d)$.

спад ее интенсивности примерно на порядок. Отметим, что область кристалла на расстоянии от поверхности, с которой проводилось легирование, от 500 до 520 мкм относится к переходному слою. Далее, в нелегированной области интенсивность линии 473 выходит на плато.

Интенсивность люминесценции на длине волны 483 нм также растет примерно на 2 порядка, но на расстоянии от 350 до 520 мкм от поверхности. Максимум ее интенсивности совпадает с максимумом интенсивности на длине волны 473 нм. В нелегированной области наблюдается слабое по интенсивности „плато“, которое может быть связано с тем, что регистрируется „хвост“ линии 473 нм.

Пространственная зависимость интенсивности люминесценции на длине волны 492 нм - другая. Ее интенсивность начинает расти практически от поверхности образца и достигает максимума на расстоянии 490 мкм от нее (на $\sim 70$ мкм дальше, чем аналогичный максимум интенсивности линии 580-630 нм). При этом интен- сивность люминесценции на длине волны 492 растет примерно на 2 порядка (рис. 1,c). После достижения максимума начинается резкий спад интенсивности люминесценции в этой области спектра. Уменьшение ее в $\sim 30$ раз происходит на расстоянии 50 мкм. Так же, как и у полосы 580-630 нм, резкий спад интенсивности люминесценции в диапазоне 492 нм заканчивается в переходной области. В нелегированной области в этом спектральном диапазоне наблюдается слабое по интенсивности „плато“, которое может быть связано с тем, что регистрируется „хвост“ линии 473 нм. На длине волны 492 нм интенсивность люминесценции „плато“ на порядок меньше интенсивности „плато“ на длине волны 483 нм. Все указанные выше зависимости характерны для всего объема образца 1.

Рассмотрим теперь результаты исследования образца $2 \mathrm{ZnSe}: \mathrm{Al}: \mathrm{Fe}$. На рис. 3 приведены карты люминесценции кристалла $\mathrm{ZnSe}: \mathrm{Al}: \mathrm{Fe}$, снятые на длинах волн 473, 492 и 580 нм, содержащие как поверхность, 


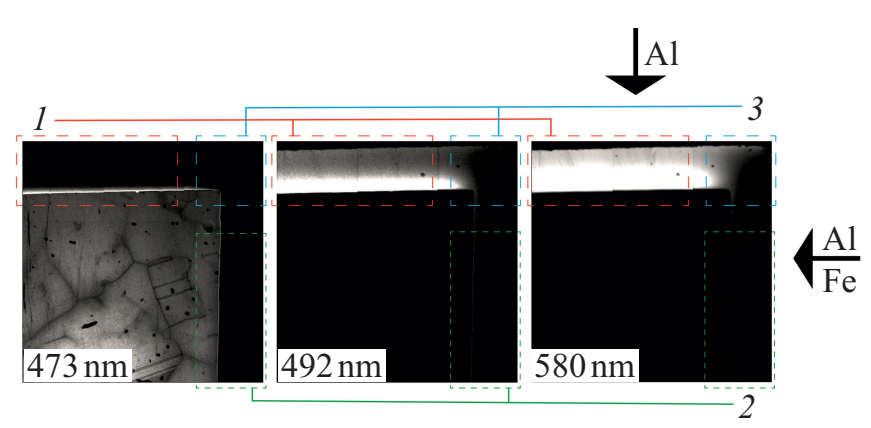

Рис. 3. Изображения особенных областей $1,2,3$ в образце $\mathrm{ZnSe}: \mathrm{Al}: \mathrm{Fe}$.

с которой шло легирование только алюминием, так и поверхность, с которой проводились легирование алюминием и железом (указано стрелками). Видно, что эти карты похожи на регистрируемые в кристалле 1. В них также можно выделить аналогичные образцу 1 области, отличающиеся по своим люминесцентным характеристикам, -- легированные области кристалла, прилегающие к поверхностям, с которых проводилось легирование алюминием, и так называемую нелегированную область внутри кристалла. Между этими областями есть узкий переходной слой. По характеристикам и размерам эти области близки к регистрируемым в образце 1 . В образце 2 можно выделить 3 специфические области:

1 - области с высокой концентрацией алюминия, в которой практически нет железа (красный пунктир);

2 - часть легированной области с высокой концентрацией алюминия и железа между переходным слоем и поверхностью образца, с которой велось легирование железом (зеленый пунктир);

3 - часть легированной области с высокой концентрацией железа и алюминия, в которой не наблюдается переходной слой (голубой пунктир).

Стоит отметить, что пунктирное выделение дано чуть шире обозначенных областей, чтобы не закрывать информативную часть карт.

На рис. $4, b-d$ приведены карты областей 1 и 3 на длинах волн 473, 492 и 580 нм соответственно. На рис. $4, b^{*}$ представлена увеличенная область 1 и переходная область, а также отмечены области $(\alpha-\delta)$, в которых записаны спектры (рис. 4, $a$ ). Профиль распределения интенсивности люминесценции из выделенных на картах областей (желтый пунктир) и профиль распределения железа показаны на рис. $4, e$.

На рис. $5, b-d$ приведены карты области 2 на длинах волн 473, 492 и 580 нм соответственно. На рис. 5, $b^{*}$ представлена увеличенная область 2 и переходная область, а также отмечены области $(\alpha-\delta)$, в которых записаны спектры (рис. 5, $a$ ). Профиль распределения интенсивности люминесценции из выделенных на картах областей (желтый пунктир) и профиль распределения железа показаны на рис. $5, e$. На рис. $5, f$ показан профиль распределения вблизи переходной области.
Из рис. 4 видно, что легированная область 1 в образце $\mathrm{ZnSe}: \mathrm{Al}: \mathrm{Fe}$ практически не отличается от аналогичной области в ZnSe:Al. В спектре люминесценции этой области также доминирует полоса 580-630 нм. Ее интенсивность, как и в образце 1 , медленно растет от края образца, с которого велось легирование алюминием. Ситуация с линиями люминесценции в диапазоне 470-500 нм в ZnSe:Al:Fe аналогична их поведению в образце 1. Переходная область между легированной областью 1 и нелегированной областью в $\mathrm{ZnSe}: \mathrm{Al}: \mathrm{Fe}$ по
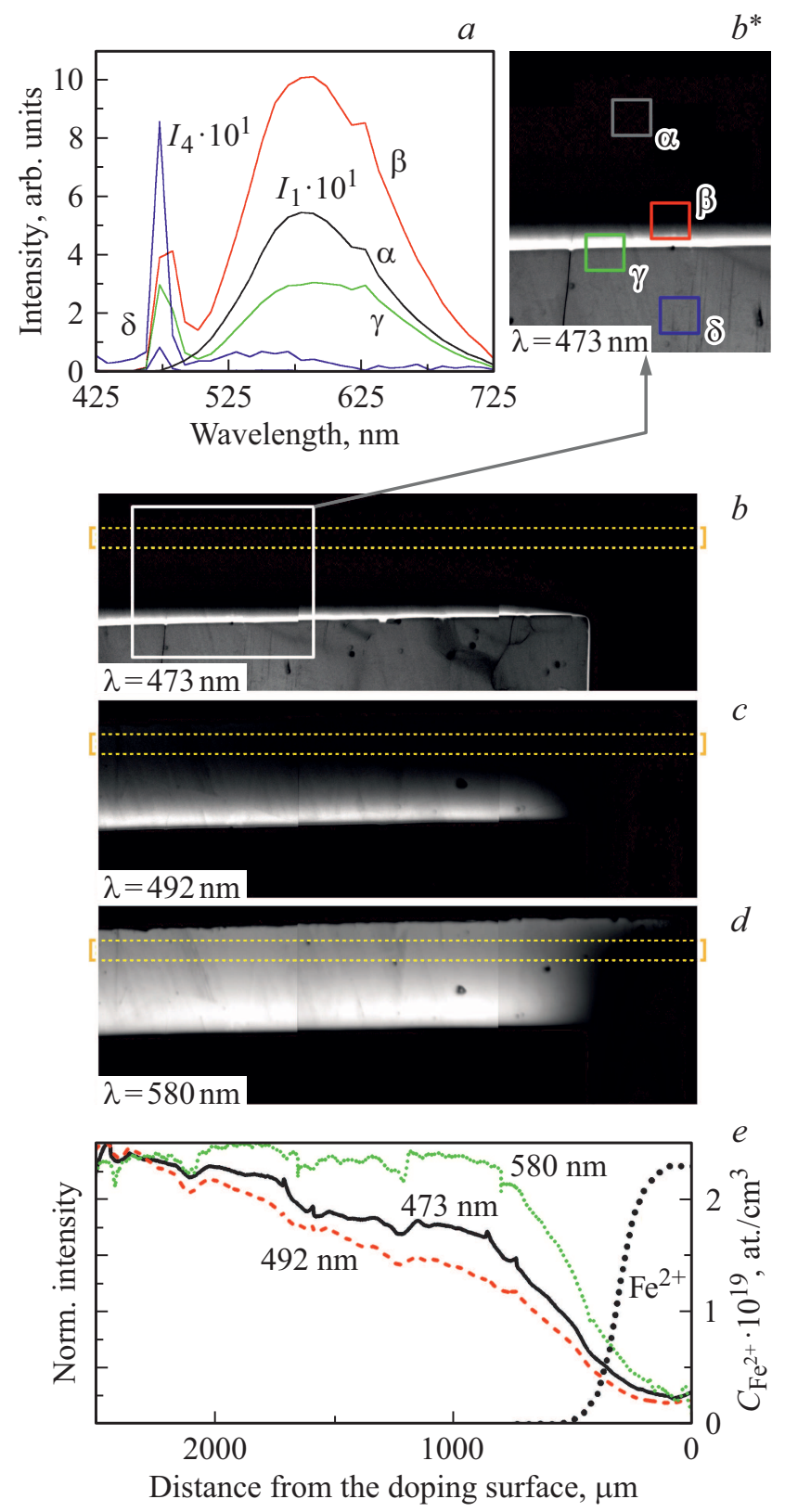

Рис. 4. Спектры люминесценции $\mathrm{ZnSe}: \mathrm{Al}: \mathrm{Fe}(a)$, полученные в точках $\alpha, \beta, \gamma, \delta$, отмеченные на увеличенной карте областей 1 и $3\left(b^{*}\right)$. Распределение люминесценции $(e)$ на длинах волн 473, 492, 580 нм и $\mathrm{Fe}^{2+}$ (черные точки) из областей (желтый пунктир), отмеченных на картах люминесценции $(b, c, d)$ на длинах волн 473, 492 и 580 нм соответственно. 

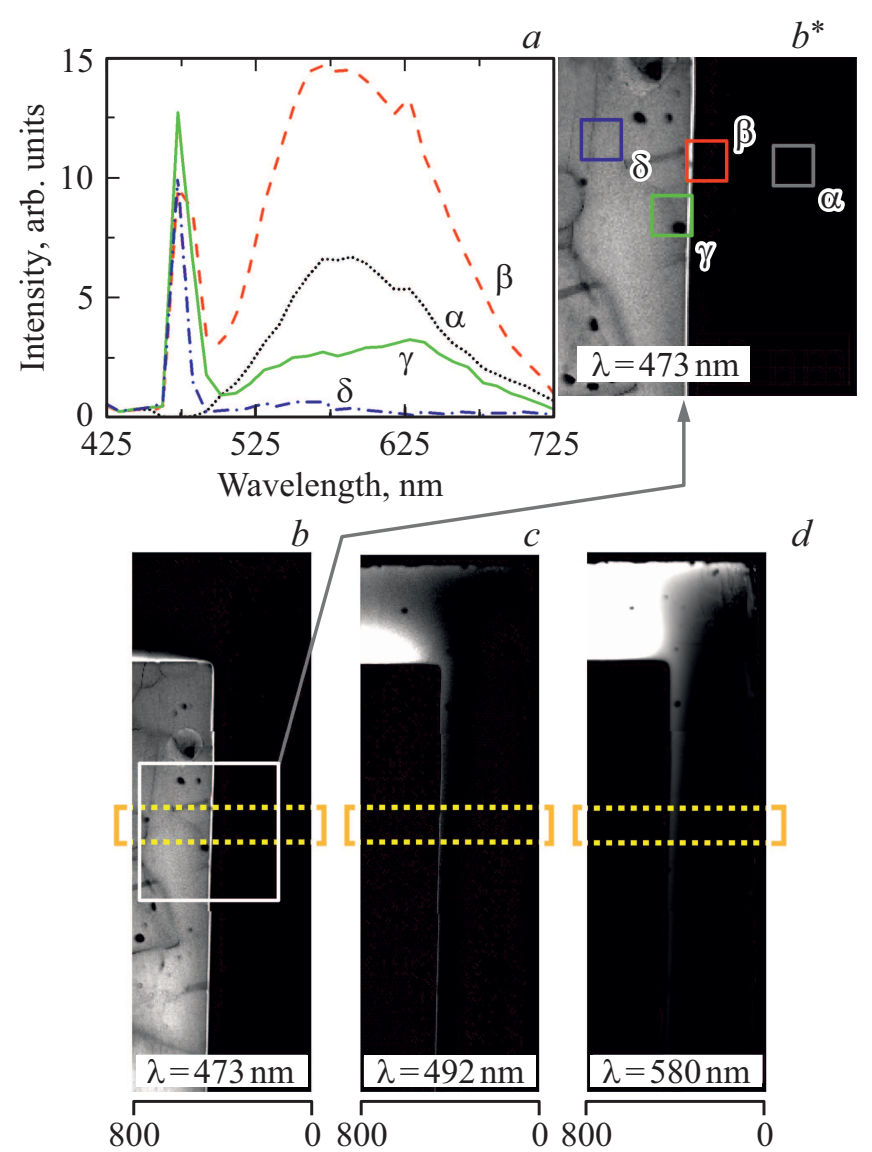

Distance from the doping surface, $\mu \mathrm{m}$

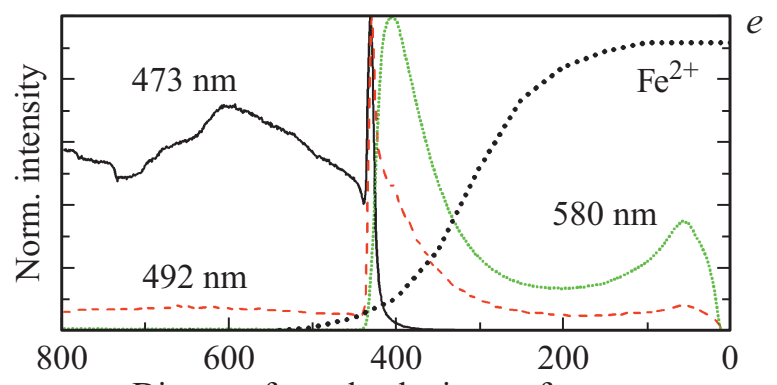

Distance from the doping surface, $\mu \mathrm{m}$

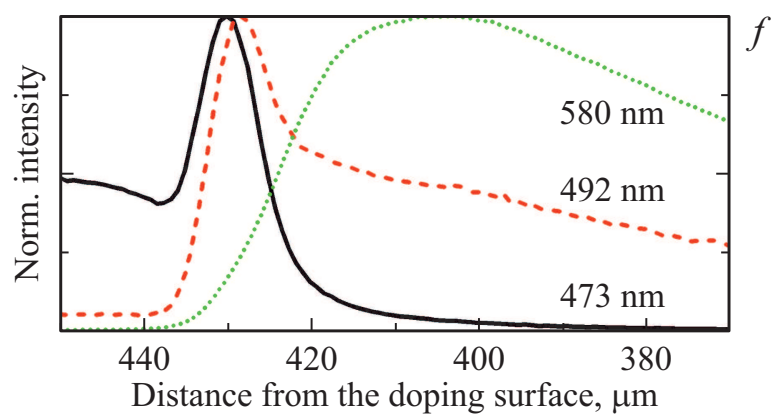

Рис. 5. Спектры люминесценции $\mathrm{ZnSe}: \mathrm{Al}: \mathrm{Fe}(a)$, полученные в точках $\alpha, \beta, \gamma, \delta$, отмеченные на увеличенной карте области $2\left(b^{*}\right)$. Распределение люминесценции $(e)$ на длинах волн 473, 492, 580 нм и $\mathrm{Fe}^{2+}$ (черные точки) из областей (желтый пунктир), отмеченных на картах люминесценции $(b, c, d)$ на длинах волн 473,492 и 580 нм соответственно. На рис. $5, f$ представлено распределение в увеличенной переходной области. своим люминесцентным характеристикам не отличается от переходной области в $\mathrm{ZnSe}: \mathrm{Al}$. Нелегированная область кристалла 2 по люминесцентным характеристикам мало отличается от аналогичной области образца 1 - в ней доминируют люминесценция связанного экситона и линия 560 нм.

Сложнее ситуация в части образца 2, легированной железом. В спектре этой области так же доминирует полоса 580-630. Однако ее интенсивность в прилегающей к поверхности кристалла области существенно меньше интенсивности этой линии в такой же области кристалла в легированной области 1. Затем по мере удаления от поверхности ее интенсивность растет. При этом в области легирования 2 нарастание идет существенно быстрее (рис. 5,d,e), чем в области легирования 3 (рис. $4, d, e)$. В первом случае интенсивность полосы люминесценции 580-630 нм выходит на максимум на расстоянии от поверхности $\sim 410$ мкм, а во втором на расстоянии 900 мкм. При этом концентрация железа спадает до значений меньше чувствительности используемой аппаратуры на расстоянии $\sim 500$ мкм от поверхности. Переходной слой между нелегированной областью образца $\mathrm{ZnSe}: \mathrm{Al}: \mathrm{Fe}$ и легированной областью 2 по своим характеристикам аналогичен переходным слоям образца $1(\mathrm{ZnSe}: \mathrm{Al})$ и легированной области 1 в образца $2(\mathrm{ZnSe}: \mathrm{Al}: \mathrm{Fe})$. Аналогично поведение и полосы 470-500 нм. Однако интенсивность линии люминесценции 475 в переходной области между легированной областью 2 и нелегированной областью несколько меньше, чем в случае легированной области 1. Отметим, что интенсивная линия люминесценции экситона наблюдается в области кристалла с достаточно высокой концентрацией железа.

\section{4. Обсуждение результатов}

Первоначально остановимся на природе линий 473, 475 и 480 нм. Линия 473 нм связана с люминесценцией экситона [12,13]. Линия 480 нм в принципе тоже может быть излучением экситона. Однако ее интенсивность зависит от мощности накачки так же, как интенсивность люминесценции линии 540-630 нм, которая, обусловлена люминесценцией ПДЦ. Интенсивность же линии 473 нм растет качественно быстрее. В работе [14] было показано, что при импульсном двухфотонном возбуждении для экситонной люминесценции характерна более резкая зависимость интенсивности люминесценции (3-4 степень), по сравнению с примесной (квадратичная). Таким образом, линия 48 нм, скорее всего, также обусловлена люминесценцией ПДЦ, а линия 473 нм люминесценцией экситона. Природа же линии 475 нм непонятна. Скорее всего, она просто представляет собой комбинацию линий 473 и 483 нм. В этом случае надо предположить, что люминесценция экситона образует узкую интенсивную полосу в переходном слое. Иначе 
объяснить пространственное поведение интенсивности люминесценции линии 475 невозможно.

Наблюдаемые в легированных областях полос люминесценции 540-630 нм можно объяснить люминесценцией на образующихся в процессе диффузии алюминия ПДЦ. В ряде работ [4,19-21,25,26] отмечалось, что в результате диффузии алюминия в ZnSe образуется целый ряд комплексов алюминия с остаточными примесями и собственными дефектами. Так, сходные с регистрируемыми в данной работе линии наблюдались в работах $[15,21]$. В этих работах исследовались кристаллы $\mathrm{ZnSe}$, легированные алюминием из расплава цинка. Регистрируемые в ней линии с максимумами люминесценции (при температуре 4 К): 632 нм - с комплексом CuZnAlZn, 597 нм - с комплексом - $\mathrm{V}_{\mathrm{Zn}} \mathrm{Al}_{\mathrm{Zn}}$, 662 нм - $\mathrm{V}_{\mathrm{Zn}}$. Учитывая, что наши эксперименты проводятся при комнатной температуре и при невысоком спектральном разрешении, не исключено, что наблюдаемые в нашей работе линии являются комбинацией этих линий. Наблюдалась в этих работах и линия, близкая по своим характеристикам регистрируемой в данной работе линии 480 нм. Авторы работы [15] связывают эту линию с люминесценцией мелкого донора $\mathrm{V}_{\mathrm{Se}} \mathrm{Na} \mathrm{Zn}$. Близкие к наблюдаемым в данной работе спектры люминесценции регистрировались также в работе [4]. В ней исследовалась люминесценция легированного индием и алюминием из расплава цинка $\mathrm{ZnSe}$ при $40 \mathrm{~K}$. Установлены люминесценция донорно-акцепторных пар в спектральном диапазоне 455-475 нм и широкая линия в диапазоне 500-730 нм с максимумом в районе 560 нм и особенностью в районе 630 нм. Аналогичные спектры наблюдались в работе [21], в которой исследовалась люминесценция $\mathrm{ZnSe}$, легированного алюминием из газовой фазы цинка. В этой работе максимум люминесценции при 630 нм связывался с комплексом $\mathrm{V}_{\mathrm{Zn}} \mathrm{Al}_{\mathrm{Zn}}$. Природа максимума люминесценции при 560 нм однозначно не установлена. Предполагается, что он обусловлен комплексом $\mathrm{V}_{\mathrm{Zn}} \mathrm{Al}_{\mathrm{Zn}}$ - мелкая фоновая примесь типа Li или Na. Таким образом, наблюдаемые в данной работе спектры люминесценции в легированной области коррелируют с наблюдаемыми ранее и связываются с комплексами алюминия, вакансиями цинка и фоновых примесей.

Однако объяснить наблюдаемые пространственные распределения интенсивности люминесценции (нарастание и резкий спад люминесценции ПДЦ на некотором расстоянии от поверхности, с которой проводилось легирование), на основании распределения ПДЦ в результате стандартной диффузии - сложно. Ранее в наших работах [16-18] по исследованию влияния легирования железом и хромом на люминесцентные характеристики $\mathrm{ZnSe}$ наблюдались полосы, параллельные поверхности, шириной в сотнимкм с повышенной интенсивностью люминесценции на определенной длине волны (ОПИЛ). Эти полосы похожи на яркие полосы переходного слоя в образце 2 на длинах волн 473 и 480 нм. Определенное сходство с ОПИЛ имеют и регистрируемые пространственные зависимости интенсивности люминесценции линии 540-630. Наблюдаемые в [16-18] ОПИЛ образуются в результате совместной с основной легирующей примесью диффузии еще нескольких элементов ПДЦ, которые образуются в зоне, из которой идет диффузия основной легирующей примеси. В случае легирования алюминием такие же процессы - образование в зоне, из которой идет диффузия алюминия, сопутствующих ПДЦ (например, $\left.\mathrm{V}_{\mathrm{Zn}}\right)$ и их диффузия в образец также возможны. Однако форма регистрируемых ОПИЛ (фронты нарастания и спада) в легированных железом и хромом образцах, в отличие от профиля линий 473 и 483 нм, носит относительно симметричный характер. Кроме того, образование ОПИЛ по предлагаемому в [16-18] механизму на длине волны излучения экситона невозможно. Также сложно объяснить с помощью этого механизма пространственные зависимости интенсивности полосы 540-630 нм.

В работе [19] исследовалось с помощью SIMS пространственное распределение алюминия в $\mathrm{ZnSe}$ в результате его диффузии при температуре $950^{\circ} \mathrm{C}$ в атмосфере газообразного цинка. Было обнаружено, что диффузия алюминия в этот материал может носить сложный характер. В этой работе наблюдалось резкое (на $\sim 4$ порядка) падение концентрации алюминия в пространственном интервале $\sim 40$ мкм. Аналогичный результат был получен этими же авторами при исследовании диффузии алюминия в ZnTe [22]. Авторы объясняли это резким уменьшением коэффициента диффузии алюминия при уменьшении его концентрации. Механизм этого явления не очень понятен, однако этот экспериментальный факт позволяет дать качественное объяснение полученным в данной работе результатам.

Действительно, если в состав ПДЦ, люминесценция которых образует линии 540-630 и 480нм, входит алюминий, то резкий спад интенсивности их люминесценции легко объясняется наблюдаемым в работе [19] спадом концентрации алюминия. Отметим, что характерные размеры областей спада концентрации алюминия в работе [19] и спада интенсивности люминесценции линий 580-630 и 480нм, регистрируемых в данной работе, сопоставимы. Отсутствие спада интенсивности люминесценции этих линий при спаде концентрации алюминия в легированной области 1 может быть связано со сложным характером комплексов. Так, при увеличении расстояния от поверхности может расти концентрация таких собственных дефектов, как $\mathrm{V}_{\mathrm{Zn}}$. Увеличение концентрации $\mathrm{V}_{\mathrm{Zn}}$ приведет к росту концентрации $\mathrm{Cu}_{\mathrm{Zn}}$. Соответственно может расти концентрация любых комплексов, в состав которых входят $\mathrm{Cu}_{\mathrm{Zn}}$ и $\mathrm{V}_{\mathrm{Zn}}$. Так, в работе [15] отмечалось, что интенсивность люминесценции, связанной с комплексами $\mathrm{Cu}_{\mathrm{Zn}} \mathrm{Al}_{\mathrm{Zn}}$ и $\mathrm{V}_{\mathrm{Zn}} \mathrm{Al}_{\mathrm{Zn}}$, меньше при высокой концентрации алюминия, чем при низкой.

Линия 480 нм может быть, как отмечалось в работе [20], обусловлена люминесценцией комплекса 
$\mathrm{V}_{\mathrm{Se}} \mathrm{Na} \mathrm{Zn}$ или каким-либо другим комплексом: фоновая примесь $\mathrm{V}_{\mathrm{Zn}}$ или $\mathrm{V}_{\mathrm{Se}}$. В этом случае ее рост в легированной области объясняется ростом концентрации $\mathrm{V}_{\mathrm{Zn}}$, а резкий спад - уменьшением концентрации этих дефектов при спаде концентрации алюминия. Однако возможно, что линия 480 нм является результатом рекомбинации носителей через какой-нибудь другой ПДЦ, в состав которого входит алюминий и некий дефект, концентрация которого растет по мере спада концентрации алюминия. Тогда резкий спад интенсивности ее люминесценции объясняется резким уменьшением концентрации алюминия.

Наблюдаемые искажения переходного слоя в областях вокруг границ зерен, пересекающихся под углами, близкими к $90^{\circ}$, связаны, по-видимому, с тем, что механизмы диффузии алюминия и других ПДЦ в этих областях отличаются от механизма диффузии в основной части кристалла.

Нелегированные области образцов 1 и 2 по люминесцентным характеристикам близки к исходным нелегированным образцам. В ее люминесценции доминирует экситонная линия, быстро спадающая при удалении от переходного слоя полоса ПДЦ - 540-630 нм, и слабая по интенсивности линия 560 нм. Отметим, что эта линия соответствует люминесценции комплекса $\mathrm{Cu}_{\mathrm{Zn}} \mathrm{V}_{\mathrm{Se}} \mathrm{Cu}_{i}$. Возможно, что произошло образование этого комплекса при загрязнении образца медью при легировании. Также возможно, что это - комплекс фоновой меди в исходном материале, который образовался в результате термообработки во время легирования. Остаточная люминесценция ПДЦ - 580-630 нм связана с „хвостом“ распределения алюминия.

Переходная область в образцах содержит узкую полосу шириной $\sim 10$ мкм с высокой интенсивностью люминесценции на длине волны $\sim 475$ нм. Эта полоса расположена в области резкого спада интенсивности люминесценции всех указанных выше ПДЦ. Природа линии люминесценции с максимумом 475 нм не очень понятна и, скорее всего, ассоциирована с люминесценцией экситона. Сильная экситонная люминесценция обычно свидетельствует о высоком совершенстве материала. Можно предположить, что в этой области кристалла резко упала концентрация точечных центров эффективной рекомбинации носителей тока. Эксперименты показывают, что эта линия наблюдается в области, где резко упала интенсивность линий 540-630 и 480. Обе эти линии связаны с ПДЦ, в состав которых входят собственные дефекты. Возможно, в этой области концентрация собственных дефектов минимальна. Отметим, что близкий экспериментальный результат наблюдался в работе [22], в которой сообщалось о регистрации с помощью EBIk узкой яркой полосы в зоне резкого спада концентрации алюминия в ZnTe. Такой контраст сигнала EBIk обычно связывают с большим временем жизни неравновесных носителей.

Влияние легирования железом на люминесцентные характеристики образцов легированного алюминием
$\mathrm{ZnSe}$ близко к его влиянию на люминесценцию $\mathrm{ZnSe}$ в видимом диапазоне. Известно $[23,24,16]$, что при легировании железом $\mathrm{ZnSe}$ подавляется люминесценция экситонов, в данном случае падает интенсивность люминесценции линии 580-630 нм. Однако влияние на люминесценцию этой линии железа в легированных областях 2 и 3 существенно различается. В легированной области 3 железо подавляет люминесценцию в области кристалла на расстоянии $\sim 800$ мкм от поверхности, с которой шло легирование железом. В легированной области 2 это расстояние существенно меньше $\sim 400$ мкм. При этом на расстоянии больше 400 мкм железо не влияет (или слабо влияет) на люминесценцию экситонов и линии 480. В то же время установлено, что железо регистрируется в зоне кристалла на расстоянии до 500 мкм от поверхности. В работах $[16,17]$ показано, что во время диффузии железа в ZnSe в кристаллы в приповерхностной области формируется, как минимум, два типа ПДЦ. В дальнейшем эти ПДЦ диффундируют в глубь кристалла. По-видимому, именно эти ПДЦ, а не ионы железа, подавляют люминесценцию экситонов и линии 540-630нм (по крайней мере в части кристалла, где концентрация железа невелика). В области, близкой к переходной области, в самой переходной области предполагается резкое изменение концентрации собственных дефектов. Высока вероятность, что ПДЦ, образовавшиеся в процессе легирования железом, также являются собственными дефектами. Возможно, их взаимодействие с дефектами в переходной области приводит к ослаблению влияния железа на люминесцентные характеристики $\mathrm{ZnSe}: \mathrm{Al}: \mathrm{Fe}$ в легированной области 2 .

В любом случае, очевидно, что легированная область в образце 2 не перекрывает всю область легирования железом. Если верно предположение, что резкий спад интенсивности люминесценции линий 580-630 и 480 нм связан с резким спадом концентрации алюминия, то это означает, что не вся активная область лазерной генерации имеет высокую концентрацию носителей заряда. Также это означает, что образец $\mathrm{ZnSe}: \mathrm{Al}: \mathrm{Fe}$ разделен на две области с качественно различной проводимостью.

Природа этого возможного эффекта, так же как и механизм образования яркой экситонной полосы и резкого спада интенсивности люминесценции линий 580-630 и 480 нм, требует дальнейших исследований.

\section{5. Заключение}

1. В работе детально исследовано пространственное распределение люминесцентных характеристик в диапазоне 0.44-0.72 мкм кристаллов $\mathrm{ZnSe}$, легированных алюминием методом термодиффузии.

2. Обнаружено, что методика легирования алюминием, используемая в работе, приводит к образованию в кристаллах двух областей - области с большей концентрацией алюминия, в которой доминирует люминесценция ПДЦ и отсутствует экситонная люминесценция, и 
области с меньшей концентрацией алюминия, в которой доминирует экситонная люминесценция.

3. Установлено, что границы этих областей, регистрируемые с помощью люминесценции, носят резкий, нехарактерный для диффузионных процессов характер.

4. Этот результат объясняется в предположении аномального механизма диффузии алюминия, предложенного в работе [19], приводящего к резкому уменьшению концентрации алюминия на некотором расстоянии от поверхности, с которой проводилось легирование. Это означает, что образец делится на две части - с высокой концентрацией носителей тока и низкой, возможно даже другого типа проводимости и резкой границей между ними.

5. Обнаружено, что в переходной области имеется узкая (шириной $\sim 10$ мкм) полоса, параллельная поверхности, с которой проводилось легирование с большой интенсивностью экситонной люминесценции.

6. Установлено, что применяемая в данной работе процедура легирования алюминием поликристаллов $\mathrm{ZnSe}$ ослабляет известный эффект подавления железом люминесценции ZnSe в видимом диапазоне.

\section{Финансирование работы}

Работа выполнена с использованием оборудования центра коллективного пользования „Технологический и диагностический центр для производства, исследования и аттестации микро- и наноструктур“ Института общей физики им. А.М. Прохорова РАН при частичной финансовой поддержке гранта РФФИ № 18-29-20048, в части, связанной с разработкой технологии и изготовлении образцов, работа поддержана грантом РНФ № 19-13-00205.

\section{Конфликт интересов}

Авторы статьи заявляют, что у них нет конфликта интересов.

\section{Список литературы}

[1] A.E. Dormidonov, K.N. Firsov, E.M. Gavrishchuk, V.B. Ikonnikov, S.Yu. Kazantsev, I.G. Kononov, T.V. Kotereva, D.V. Savin, N.A. Timofeeva. Appl. Phys. B. Lasers and Optics, 122, 211 (2016).

[2] S.B. Mirov, V.V. Fedorov, D. Martyshkin, I.S. Moskalev, M. Mirov, S. Vasilyev. IEEE J. Select. Top. Quant. Electron., 21 (1), 292 (2014).

[3] S.S. Balabanov, K.N. Firsov, E.M. Gavrishchuk, V.B. Ikonnikov, S.Y. Kazantsev, I.G. Kononov, D.V. Savin, N.A. Timofeeva. Laser Phys. Lett., 15 (4), 045806 (2018).

[4] A.N. Georgobiani, U.A. Aminov, Yu.V. Korostelin, V.I. Kozlovsky, A.S. Nasibov, P.V. Shapkin. J. Cryst. Growth, 184-185, 470 (1998).

[5] B. Reinhold, M. Wienecke. J. Cryst. Growth, 204 (4), 434 (1999).

[6] M. Prokesch, K. Irmscher, J. Gebauer, R. Krause-Rehberg. J. Cryst. Growth, 214-215, 988 (2000).
[7] L. Luke, V.V. Fedorov, I. Moskalev, A. Gallian, S.B. Mirov. Proc. SPIE, Solid State Lasers XV: Technology and Devices, 6100, 61000Y (2006).

[8] O. Gafarov, R. Watkins, V. Fedorov, S. Mirov. OSA Laser Congress (ASSL, LAC), AW3A.4 (2018).

[9] В.П. Калинушкин, О.В. Уваров. ЖТФ, 86 (12), 119 (2016).

[10] V. Kalinushkin, O. Uvarov, A. Gladilin. J. Electron. Mater., 47, 5087-5091 (2018).

[11] K.N. Firsov, E.M. Gavrishchuk, V.B. Ikonnikov, S.Yu. Kazantsev, I.G. Kononov, S.A. Rodin, D.V. Savin, N.A. Timofeeva. Laser Phys. Lett., 13 (1), 015001 (2016).

[12] Е.М. Гаврищук, А.А. Гладилин, В.П. Данилов, В.Б. Иконников, Н.Н. Ильичев, В.П. Калинушкин, А.В. Рябова, М.И. Студеникин, Н.А. Тимофеева, О.В. Уваров, В.А. Чапнин. Неорг. матер., 52 (11), 1180 (2016).

[13] Д.Д. Недеогло. Электрические и люминесцентные свойства селенида цинка (Кишинев, Штиинца, 1984) с. 153.

[14] А.А. Гладилин, В.П. Данилов, Н.Н. Ильичев, В.П. Калинушкин, М.И. Студеникин,О.В. Уваров, В.А. Чапнин, А.В. Рябова, А.В. Сидорин, Э.С. Гулямова,В.В. Туморин, П.П. Пашинин. ФТП, 54 (1), 48 (2020).

[15] G.N. Ivanova, D.D. Nedeoglo, N.D. Negeoglo, V.P. Sirkeli, I.M. Tiginyanu, V.V. Ursaki. J. Appl. Phys., 101, 063543 (2007).

[16] А.А. Гладилин, Н.Н. Ильичев, В.П. Калинушкин, М.И. Студеникин, О.В. Уваров, В.А. Чапнин, В.В. Туморин, Г.Г. Новиков. ФТП, 53 (1), 5 (2019).

[17] С.С. Балабанов, Е.М. Гаврищук, А.В. Гладилин, В.Б. Иконников, Н.И. Ильичев, В.П. Калинушкин, С.А. Миронов, Д.В. Савин, М.И. Студеникин, Н.А. Тимофеева, О.В. Уваров, В.А. Чапнин. Неорг. матер., 55 (5), 45 (2019).

[18] Gladilin, S. Chentsov, O. Uvarov, S. Nikolaev, V. Krivobok, V. Kalinushkin. J. Appl. Phys., 126, 015702 (2019).

[19] Y. Namikawa, S. Fujiwara, T. Kotani. J. Cryst. Growth, 229, 92 (2001).

[20] В.С. Вавилов, А.А. Клюканов, К.Д. Сушкевич, М.В. Чукичев, Р.Р. Резванов, Е.К. Сушкевич. ФТТ, 39 (9), 1526 (1997).

[21] J.C. Bouley, P. Blaneonnier, A. Herman, Ph. Ged, P. Henoe, J.P. Noblane. J. Appl. Phys., 46 (8), 3549 (1975).

[22] T. Tanaka, N. Murata, K. Saito, M. Nishio, Q. Guo, H. Ogawa. Phys. Status Solidi B, 244 (5), 1685 (2007).

[23] L.L. Kulyuk, R. Laiho, A.V. Lashkul, E. Lahderanta, D.D. Nedeoglo, N.D. Nedeoglo, I.V. Radevici, A.V. Siminel, V.P. Sirkeli, K.D. Sushkevich. Physica B, 405, 4330 (2010).

[24] M. Surma, M. Godlewski, T.P. Surkova. Phys. Rev. B, 50 (12), 8319 (1994).

[25] M. Aven, R.E. Halsted. Phys. Rev., 137 (1A), 228 (1965).

[26] Ю.Ф. Ваксман, Н.В. Малушин, В.В. Сердюк. ЖПС, 25 (б), 832 (1976).

Редактор А.Н. Смирнов

Физика и техника полупроводников, 2021, том 55, вып. 5 


\title{
Study of spatial distribution of luminescence in the wavelength range of $0.44-0.75 \mu \mathrm{m}$ in CVD-ZnSe doped with aluminum and iron
}

V.P. Kalinushkin ${ }^{1}$, A.A. Gladilin ${ }^{1}$, O.V. Uvarov ${ }^{1}$, S.A. Mironov ${ }^{1}$, N.N. Ilyichev ${ }^{1}$, M.I. Studenikin ${ }^{1}$, V.A. Chapnin ${ }^{1}$, N.A. Timofeeva ${ }^{2}$, E.M. Gavrishchuk ${ }^{2}$, S.A. Rodin'2, V.B. Ikonnikov'2, G.G. Novikov ${ }^{3}$

${ }^{1}$ Prokhorov General Physics Institute, 119991 Moscow, Russia

2 Devyatykh Institute of Chemistry

of High-Purity Substances,

Russian Academy of Sciences, 603951 Nizhny Novgorod, Russia

${ }^{3}$ National Research Nuclear University „MEPhl“, 115409 Moscow, Russia

\begin{abstract}
Spatial distribution of luminescence characteristics of CVD-ZnSe doped with Aluminum and both Aluminum and Iron by thermal diffusion were studied. The diffusion method leads to formation of two areas in crystal volume: area with high aluminum concentration in which the luminescence of defective-impurity centers dominates and exciton luminescence is absent and area with low aluminum concentration in which exciton luminescence dominates. The border of two areas recognized on luminescence map is sharp that not corresponded to diffusion nature. The result is explained by assuming the anomalous nature of aluminum diffusion, leading to a sharp change in the aluminum concentration at a certain distance from the doping surface. Method of aluminum doping process applied in present paper leaded to weakens of wellknown luminescence suppression effect by iron ions in $\mathrm{ZnSe}$.
\end{abstract}

